\title{
Influence of pyrrhotite content on the mechanical and chemical behaviour of cemented paste backfill
}

\author{
J. Godbout Industrial NSERC Polytechnique-UQAT Chair Environment and Mine Waste Management, \\ Université du Québec en Abitibi-Témiscamingue, Canada \\ B. Bussière Industrial NSERC Polytechnique-UQAT Chair Environment and Mine Waste Management, \\ Université du Québec en Abitibi-Témiscamingue, Canada
}

M. Benzaazoua Industrial NSERC Polytechnique-UQAT Chair Environment Mine Waste Management, Université du Québec en Abitibi-Témiscamingue, Canada

M. Aubertin Industrial NSERC Polytechnique-UQAT Chair Environment and Mine Waste Management, Université du Québec en Abitibi-Témiscamingue, Canada

\begin{abstract}
The chemical weathering related to sulphide minerals oxidation within mine backfill in underground stopes can cause serious problems, such as the loss of mechanical strength due to sulphate attack. This can also lead, under specific (extreme) conditions, to excessive self-heating of the backfill and to oxygen depleted atmosphere. Previous studies indicate that sulphide minerals contained in cemented paste backfill (CPB) are less reactive (i.e. less prone to oxidation) than those contained in hydraulic backfill (HB) because the favourable hydraulic properties of $C P B$ can help maintain a high degree of water saturation (often more than $85 \%$ ) in the fill material. This paper presents results from an investigation of the influence of pyrrhotite content on the physico-chemical behaviour of cemented paste and hydraulic backfills. Oxygen-consumption (OC) tests, uniaxial compressive strength (UCS) tests, and a post-testing characterisation were performed on different mixtures of cemented backfills made of tailings with 5\% wt of binder and various percentages of pyrrhotite (2 to 15\%). Tailings without binder were also assessed with the OC test (as control samples). All samples were cured under controlled temperature and moisture conditions $\left(30^{\circ} \mathrm{C}\right.$ and $100 \%$ respectively) to simulate curing under warm mine site conditions, for periods of $3,7,28,56,182$, and 365 days. The OC tests results show that pyrrhotite-rich tailings without binder can be very reactive; the consumed oxygen flux measured can exceed $35 \mathrm{~mol} / \mathrm{m}^{2} /$ day when these are exposed to atmospheric concentration. OC tests also show that the addition of binder (Portland cement) in the backfill mixtures reduces their reactivity; a more significant reduction was observed for paste backfill samples compared with hydraulic backfill specimens. The OC tests results furthermore indicate a decrease of the control samples (tailings without binder) reactivity over time, suggesting that other factors, such as passivation of the pyrrhotite grains surface during weathering, could also influence the evolution of backfill reactivity. The UCS tests results show that paste backfill samples reached higher strength than hydraulic backfill. However, a progressive loss of strength was also observed for all backfill mixtures after a few months, probably due to sulphate attack.
\end{abstract}

\section{Introduction}

Oxidation of sulphide minerals contained in cemented mine backfill (CB), and the associated oxygen consumption, can have serious consequences. From an environmental point of view, the sulphide oxidation may cause the generation of acid mine drainage that affect the quality of groundwater (e.g. Aubertin et al., 2002). During mining operations, the loss of backfill strength, related to a sulphate attack for instance, can also affect the mine production (e.g. Benzaazoua et al., 1999, 2002, 2004; Bertrand et al., 2000). Another phenomenon that can be dangerous to mine workers is oxygen depletion in areas where insufficient convective overturn and circulation of air take place (Philips et al., 2008). Furthermore, under specific circumstances, the sulphides oxidation in mining wastes, including backfill, may be sufficiently rapid that self-heating occurs and lead to ignition, which creates serious problems for the mine operation (open fires and $\mathrm{SO}_{2}$ emissions) (Rosenblum et al., 1982, 2001; Rosenblum and Spira, 1995; Bernier and Li, 2003). 
Although a binder improves the mechanical and chemical stability of CBs (Benzaazoua et al., 1999, 2002; Benzaazoua and Belem, 2000), cases where atmosphere oxygen depletion (Bayah et al., 1984) and selfheating of backfilled stopes occurred (Bernier and Li, 1998, 2003; Liu et al. 1999; Benzaazoua et al., 2001) have been reported in literature. These studies suggest that the major predisposition for a rapid sulphide oxidation in $\mathrm{CB}$ would be the crystallographic form of the pyrrhotite (monoclinic being more reactive than hexagonal form) and relatively high pyrrhotite (Po) content in the backfill. However, these assumptions not yet been confirmed by systematic investigations (to the authors' knowledge).

This paper presents some key results obtained from oxygen consumption (OC) tests, uniaxial compressive strength (UCS) tests, and a post-testing characterisation performed on cemented (5\% wt binder content) backfills (hydraulic and paste) containing between 2 and 15\% Po. The response of tailings without binder was also assessed with the OC test, to provide a basis (as control samples) for the investigation.

\section{Experimental program}

To evaluate the influence of pyrrhotite on the mechanical and chemical behaviour of cemented backfills (hydraulic and paste), different tests were performed: oxygen consumption (OC, expressed as oxygen flux in $\mathrm{mol} / \mathrm{m}^{2} /$ day) tests on cemented backfills containing different pyrrhotite contents with various recipes, uniaxial compressive strength (UCS) tests on cured samples, and chemical/mineralogical characterisation tests performed on post-UCS tested samples. Overall, ten hydraulic backfill recipes and six paste backfill recipes were prepared; a few sample results are presented in this paper (more details will appear in Godbout, 2010). The hydraulic backfills had pyrrhotite contents of 2 and $8 \%$, and were prepared at a solids percentage of $65 \%$. The cemented paste backfills had pyrrhotite contents of 8 and $15 \%$, and were prepared to reach a $200 \mathrm{~mm}$ slump (ASTM C 143-90).

\subsection{Materials}

\subsubsection{Tailings and inert materials}

Tailings, containing $28 \%$ pyrrhotite, were mixed with two inert materials to reach the targeted pyrrhotite contents. For each mixture, the particle size distribution met the following criteria: $<20 \%$ smaller than $20 \mu \mathrm{m}$ for hydraulic backfills; $>20 \%$ smaller than $20 \mu \mathrm{m}$ for paste backfills (defined by one industrial partner of the authors, interested by this study).

The physical properties of the different materials were determined with a Malvern laser Mastersizer ${ }^{\text {(for }}$ the grain-size distribution), a Micromeritics helium pycnometer Accupyc 1330 (for the relative density of the solid grains $D_{r}$ ), and a surface area analyser Micromeritics Gimini III 2375 (for the specific surface area $S_{a}$ ). The mineralogical composition of the tailings and of the inert materials was evaluated by X-ray diffractometer (Bruker A.X.S. model D8 Advance). The minerals quantification was performed using the Rietveld method (Taylor and Hinczak, 2001) with the Bruker's TOPAS software. The main physical properties of the tailings and inert materials are presented in Table 1. The particle size distributions of the different hydraulic and paste backfill recipes (with a proportion of pyrrhotite from 2 to $15 \%$ ), resulting from the mixtures of the tailings and the inert materials, are shown in Figure 1.02 
Table 1 Main physical properties of the tailings and the inert materials

\begin{tabular}{|c|c|c|c|}
\hline \multicolumn{4}{|c|}{ Physical Properties } \\
\hline & \multirow[t]{2}{*}{ Tailings } & \multicolumn{2}{|c|}{ Inert Material } \\
\hline & & $H B$ & $C P B$ \\
\hline$\%<2 \mu \mathrm{m}$ & 7 & 2 & 7 \\
\hline$\%<80 \mu \mathrm{m}$ & 75 & 17 & 53 \\
\hline $\mathrm{D}_{10}(\mu \mathrm{m})$ & 4 & 31 & 4 \\
\hline $\mathrm{C}_{\mathrm{U}}=\mathrm{D}_{60} / \mathrm{D}_{10}$ & 13 & 12 & 31 \\
\hline $\mathrm{D}_{\mathrm{r}}$ & 3.33 & 2.68 & 2.69 \\
\hline $\mathrm{S}_{\mathrm{a}}\left(\mathrm{m}^{2} / \mathrm{g}\right)$ & 1.895 & nd & nd \\
\hline
\end{tabular}

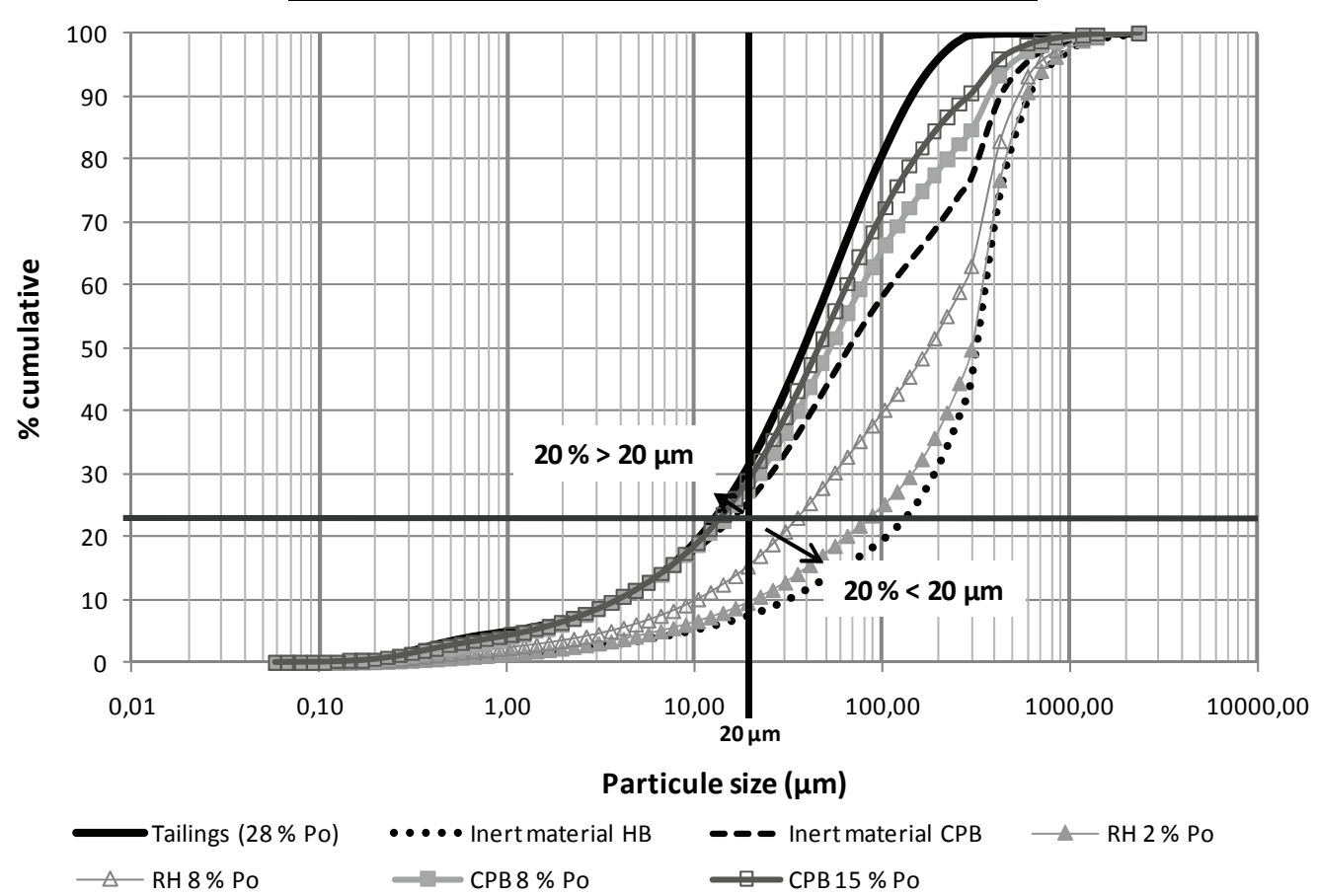

Figure 1 Backfills grain-size distribution curves

The tailings used in the various mixtures are characterised by a coefficient of uniformity $\left(\mathrm{C}_{\mathrm{U}}\right)$ of 13 , a percentage smaller than $2 \mu \mathrm{m}$ and $80 \mu \mathrm{m}$ of $7 \%$ and $75 \%$ respectively, and by a grain diameter corresponding to $10 \%$ cumulative $\left(\mathrm{D}_{10}\right)$ of $4 \mu \mathrm{m}$. The particle size characteristics of the backfill vary with the inert material quantities added to the mixture, based on the pyrrhotite content targeted. The inert material used for the HB preparation has a $\mathrm{C}_{\mathrm{U}}$ of 12 , a percentage smaller than $2 \mu \mathrm{m}$ and $80 \mu \mathrm{m}$ of 2 and $17 \%$ respectively, and a $\mathrm{D}_{10}$ of $31 \mu \mathrm{m}$. The inert material used for the CPB preparation has a $\mathrm{C}_{\mathrm{U}}$ of 31 , a percentage smaller than $2 \mu \mathrm{m}$ and $80 \mu \mathrm{m}$ of 7 and $53 \%$ respectively, and a $\mathrm{D}_{10}$ of $4 \mu \mathrm{m}$.

The relative density of the solid grains $\left(\mathrm{D}_{\mathrm{r}}=3.33\right)$ reflects the heavy metal content in the tailings, which are rich in pyrrhotite (compared to the inert materials, with $\mathrm{D}_{\mathrm{r}} \approx 2.7$ ). The main minerals identified in the tailings are typical of ultramafique nickel mines (e.g. Thomson and Raglan mines) with primarily pyrrhotite and troilite, with traces of pyrite and chalcopyrite. These include also a gangue made up of muscovite, actinolite, chlorite, lizardite, and albite. The main minerals identified in the inert materials are, by order of importance, quartz, albite, microcline, diopside, muscovite, and actinolite. 


\subsubsection{Binder and mixing water}

Results with a single type of binder, used for the preparation of the backfill recipes, are presented here (results with other binders can be found in Godbout, 2010). The binder is a Portland cement type $10\left(\mathrm{CP}_{10}\right)$, selected by our industrial partner. This cement however is not typical of a $\mathrm{CP}_{10}$, as it contains more $\mathrm{SiO}_{2}$ than a standard Portland cement type 10, which should make it more resistant to sulphates. The proportion of binder added to the tailings mixtures is $5 \%$ by dry weight for all the backfill recipes.

Tap water was used as mixing water. The tap water has a $\mathrm{pH}$ of 7.89 , a low conductivity around $270 \mu \mathrm{S}$ (versus $>2,400 \mu \mathrm{S}$ for pore water in the tailings) and low sulphate content $(<45 \mathrm{ppm})$. The tailings pore water has a $\mathrm{pH}$ value close to neutrality (6.66), with sulphur concentration in the form of sulphates around $15,000 \mathrm{ppm}$. This high sulphate content could have an impact on the strength gain of the different backfill recipes tested (Benzaazoua et al., 2004).

\subsection{Methods}

\subsubsection{OC test}

In OC tests, a layer of the tested material (less than $2.5 \mathrm{~cm}$ thick) is placed at the bottom of a cylinder and is exposed to air for a sufficiently long period, until stationary conditions have been reached. The cylinder is then closed and sealed for oxygen concentration measurements (with a Teledyne oxygen sensor class R-17A; resolution of $0.1 \% \mathrm{O}_{2}$ ) for a period of three to five hours. In order to monitor the eventual $\mathrm{SO}_{2}$ emissions due to pyrrhotite oxidation reactions in the $\mathrm{CB}$, gas sampling and analysis using a gas chromatograph were carried out at the end of each test (see the test set up in Figure 2). The sampling procedure consisted of inserting a $5 \mathrm{~mL}$ syringe with a gas-tight seal into the septum stopper to retrieve a $2 \mathrm{~mL}$ gas sample. The gas analysis was performed with an Agilent 3000A MicroGC equipped with both a molecular sieve and a polarity-based separation column. The MicroGC is equipped with a defined volume injection loop to ensure consistent sample injection and is controlled with the Agilent Cerity Networked Data System software for chemical quality assurance - quality control (QA-QC). Calibration was performed using certified gas standards containing 5, 10, 15 and $20.8 \%$ of $\mathrm{O}_{2}$, and 10,500 and $1,000 \mathrm{ppm}$ of $\mathrm{SO}_{2}$. Since the measurements performed during the $\mathrm{OC}$ tests did not detect $\mathrm{SO}_{2}$ production, these results will not be discussed further in the following.

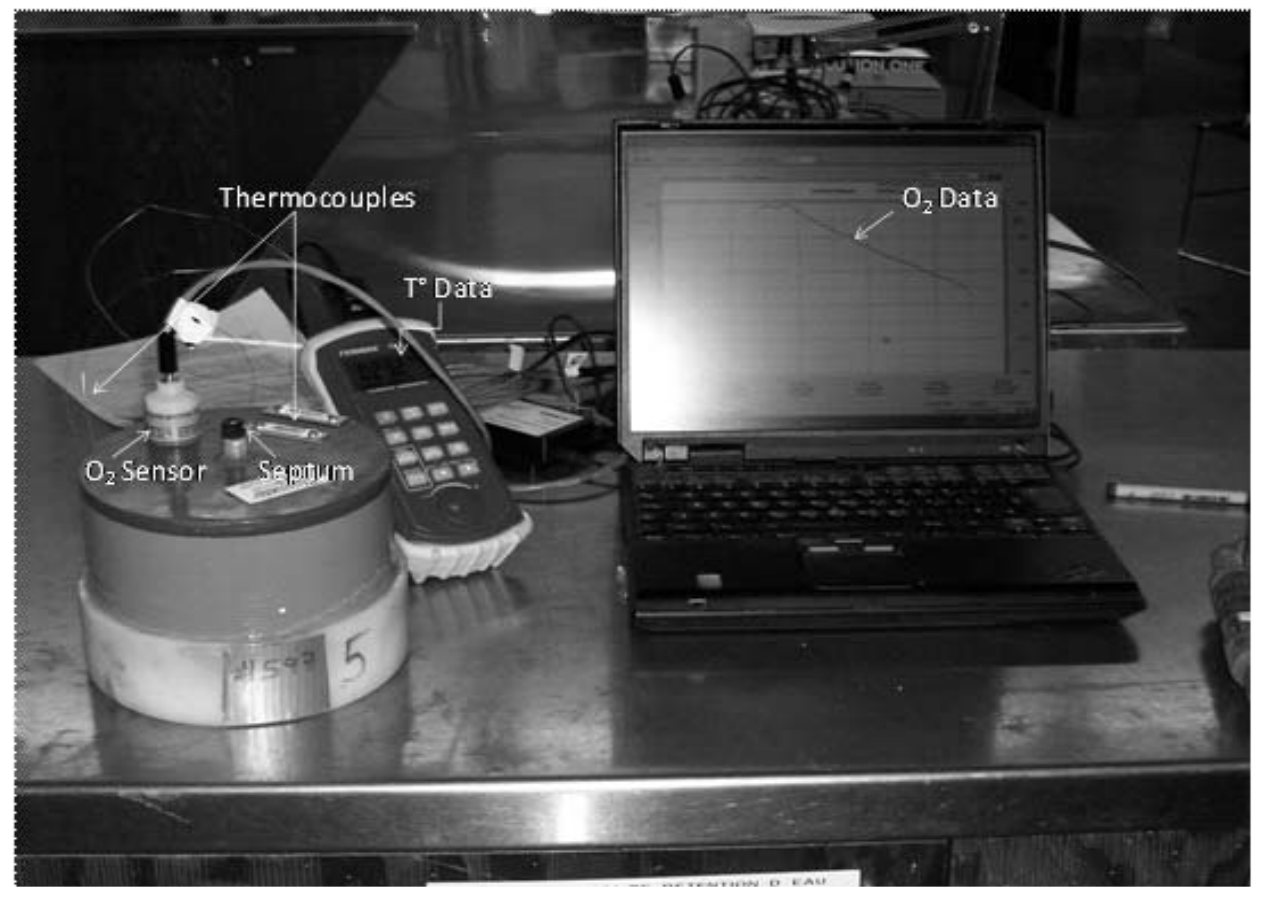

Figure 2 Experimental setup for the $\mathrm{OC}$ tests 
All samples submitted to the OC tests were poured into moulds with a diameter of $15.5 \mathrm{~cm}$ and cured under controlled temperature and moisture conditions $\left(30^{\circ} \mathrm{C}\right.$ and $100 \%$ respectively) to simulate warm mine site conditions for periods of $3,7,28,56,182$, and 365 days of curing. The hydraulic backfills were poured in moulds with a drainage port to simulate field conditions. To evaluate the effect of binder, OC tests were also performed on control samples (i.e. tailings without binder) having the same pyrrhotite contents as the corresponding cemented backfill samples (2,8 and 15\%). The control samples were prepared with the design criteria of the paste backfill mixtures.

During the $\mathrm{OC}$ tests, it is assumed that the progressive drop in oxygen concentration is mainly induced by the sulphides reactivity, which can then be expressed in terms of consumed oxygen flux. The relationship between the oxygen flux (or sulphide reactivity) and the decrease of oxygen concentration in the sealed chamber is based on fundamental gas diffusion laws (here, only Fickian gas transport mechanisms are considered). Solving Fick's second law expressed with a first-order kinetic reaction term and for the conditions $\mathrm{C}(\mathrm{z})=\mathrm{C}_{0}$ at $\mathrm{z}=0$ and $\mathrm{C}(\mathrm{z})=0$ as $\mathrm{z} \rightarrow \infty$, gives the following equation for the oxygen flux $\mathrm{F}_{\mathrm{L}}$ under steady state conditions (Elberling et al., 1994; Elberling and Nicholson, 1996):

$$
F_{L}=C_{0}\left(K_{r} D_{e}\right)^{1 / 2}
$$

where $\mathrm{K}_{\mathrm{r}}$ is the first-order reaction rate coefficient (corresponding to pyrrhotite oxidation rate), $\mathrm{D}_{\mathrm{e}}$ is the effective diffusion coefficient and $C_{0}$ is the initial (atmospheric) concentration of oxygen. Solving the continuity equation (which reflects the oxygen being depleted in the head space of the cell) for the initial condition $\mathrm{C}=\mathrm{C}_{0}$ at $\mathrm{t}=0$, the following solution is obtained (Elberling et al., 1994; Elberling and Nicholson, 1996):

$$
\ln \left(C / C_{0}\right)=-t\left(K_{r} D_{e}\right)^{1 / 2}(A / V)
$$

where $\mathrm{A}$ and $\mathrm{V}$ are the area and the volume of the source reservoir respectively.

The slope of the $\ln \left(\mathrm{C} / \mathrm{C}_{0}\right)$ versus time plot gives the value of $-\left(\mathrm{K}_{\mathrm{r}} \mathrm{D}_{\mathrm{e}}\right)^{1 / 2}$ when $\mathrm{A} / \mathrm{V}$ is known. As steady state conditions are assumed to be maintained during the short duration test, the term $-\left(\mathrm{K}_{\mathrm{r}} \mathrm{D}_{\mathrm{e}}\right)^{1 / 2}$ can be substituted into Equation (1) to evaluate the oxygen flux at the surface of a thick deposit, which is then related to the oxygen consumption from the sulphide minerals. The standard OC test applies for a small change in oxygen concentration $\left(2\right.$ to $\left.3 \% \mathrm{O}_{2}\right)$ in the headspace over the three to five hour measuring period. The change in oxygen concentration within the pore space during the testing period is sufficiently small so it can be conveniently assumed that a (pseudo) steady state is maintained. More details on the interpretation method for the standard OC method are given in Elberling et al. (1993, 1994), Elberling and Nicholson (1996), Mbonimpa et al. (2002; 2003), Ouellet et al. (2003, 2005, 2006), Gosselin (2007).

\subsubsection{Complementary tests and measurements}

Uniaxial compressive strength (UCS) measurements were performed in parallel with the OC tests on all backfill samples (moulds of $5.08 \times 10.16 \mathrm{~cm}$ ) in triplicate, according to standard ASTM C39, at curing times of $7,28,56,182$, and 365 days. The objective of UCS tests was to obtain a measure that reflects simultaneously the chemical and mechanical responses of the backfill, knowing that the two types of response should be related.

As was done elsewhere (e.g. Bernier and Li, 2003), a post-testing characterisation was conducted to obtain a better understanding of pyrrhotite oxidation mechanisms in CB. The post-testing characterisation was performed on selected samples of backfills cured during 28 days (short term) and 182 days (long term); only results at long curing time (182 days) are presented here (see Godbout, 2010 for more details). The posttesting characterisation results presented are XRD mineralogical analyses for the identification and a semiquantification of well-crystallised expansive cementitious minerals.

As that the degree of saturation has a great influence on the material behaviour (particularly on the effective diffusion coefficient $\mathrm{D}_{\mathrm{e}}$ that controls oxygen flux; see Equation 1), the water content was also evaluated after each series of tests, according to standard ASTM D2216-98. The degree of saturation of the studied backfill mixtures was evaluated on the UCS post-testing samples (in triplicate) at curing times of 7,28, 56, 182, and 
365 days; the average of the three $\mathrm{S}_{\mathrm{r}}$ values was used for the interpretation of the OC tests conducted at the same time.

\section{$3 \quad$ Results}

\subsection{OC tests results}

\subsubsection{Control samples}

Figure 3 presents the evolution of the oxygen flux calculated for the control samples, according to the pyrrhotite content of the different studied mixtures.

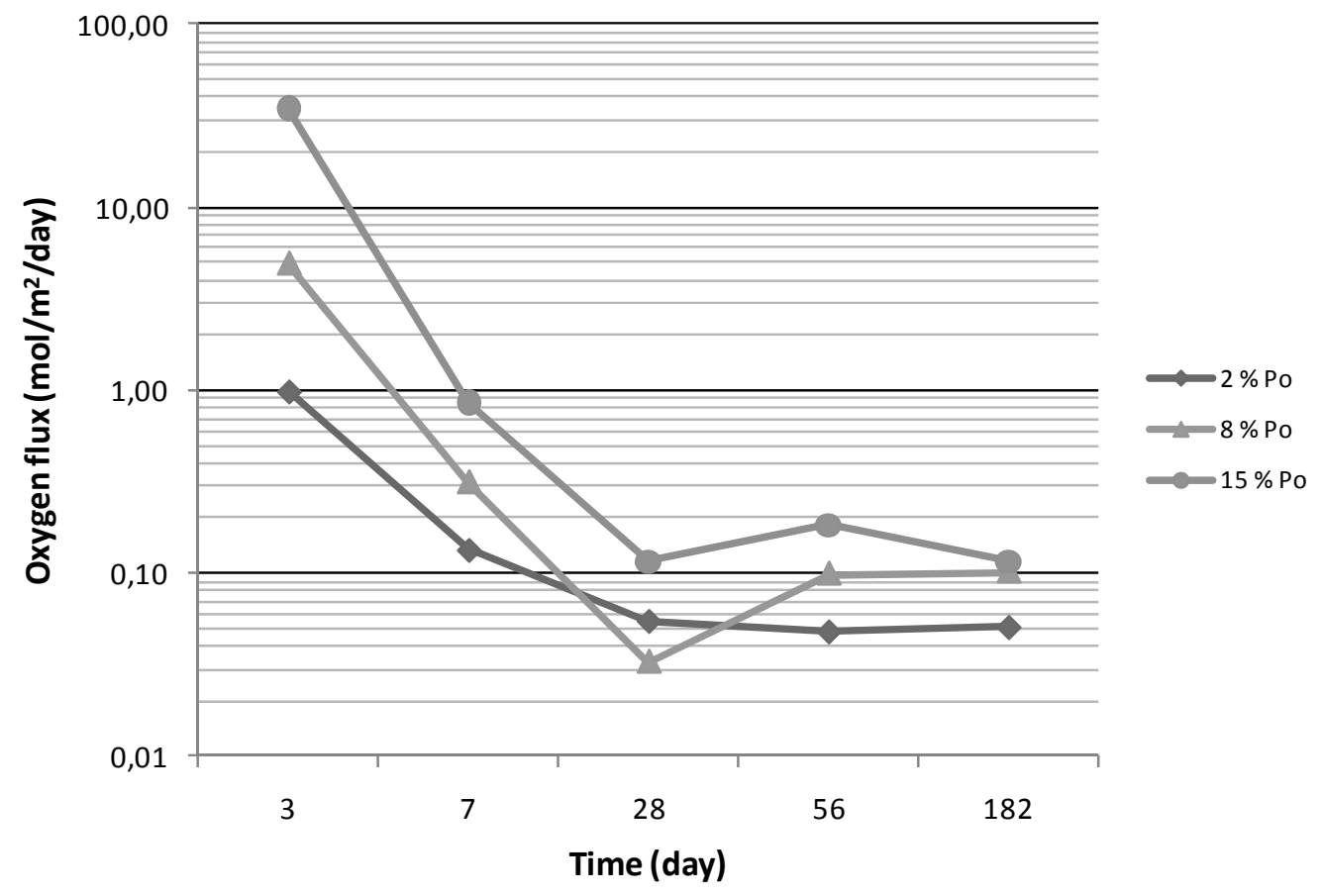

Figure 3 Oxygen flux determined on the control samples for 3 pyrrhotite contents in the mixture

Figure 3 shows that the consumed oxygen flux of the control samples can reach values as high as $35 \mathrm{~mol} \mathrm{O} / \mathrm{m}^{2} /$ day after three days. To the authors' knowledge, very few oxygen fluxes higher than $5 \mathrm{~mol} \mathrm{O}_{2} / \mathrm{m}^{2} /$ day have been reported in the literature (e.g. Elberling et al., 1993, 1994; Elberling and Nicholson, 1996; Tibble and Nicholson, 1997; Elberling and Damgaard, 2001; Ouellet et al. 2006). Figure 3 also shows a decrease of the oxygen flux over time for all control samples (typically from more than $35 \mathrm{~mol} \mathrm{O} / 2 / \mathrm{m}^{2} /$ day to below $0.13 \mathrm{~mol} \mathrm{O} / \mathrm{m}^{2} /$ day after 182 days). Consumed oxygen flux results indicate that, as expected, the reactivity is a function of the proportion of pyrrhotite in the tailings.

\subsubsection{Oxygen flux in cemented backfills}

Figure 4 shows the consumed oxygen flux evolution for the hydraulic and paste backfills as a function of the curing time. Unmarked lines represent the oxygen flux evolution of the control samples. 


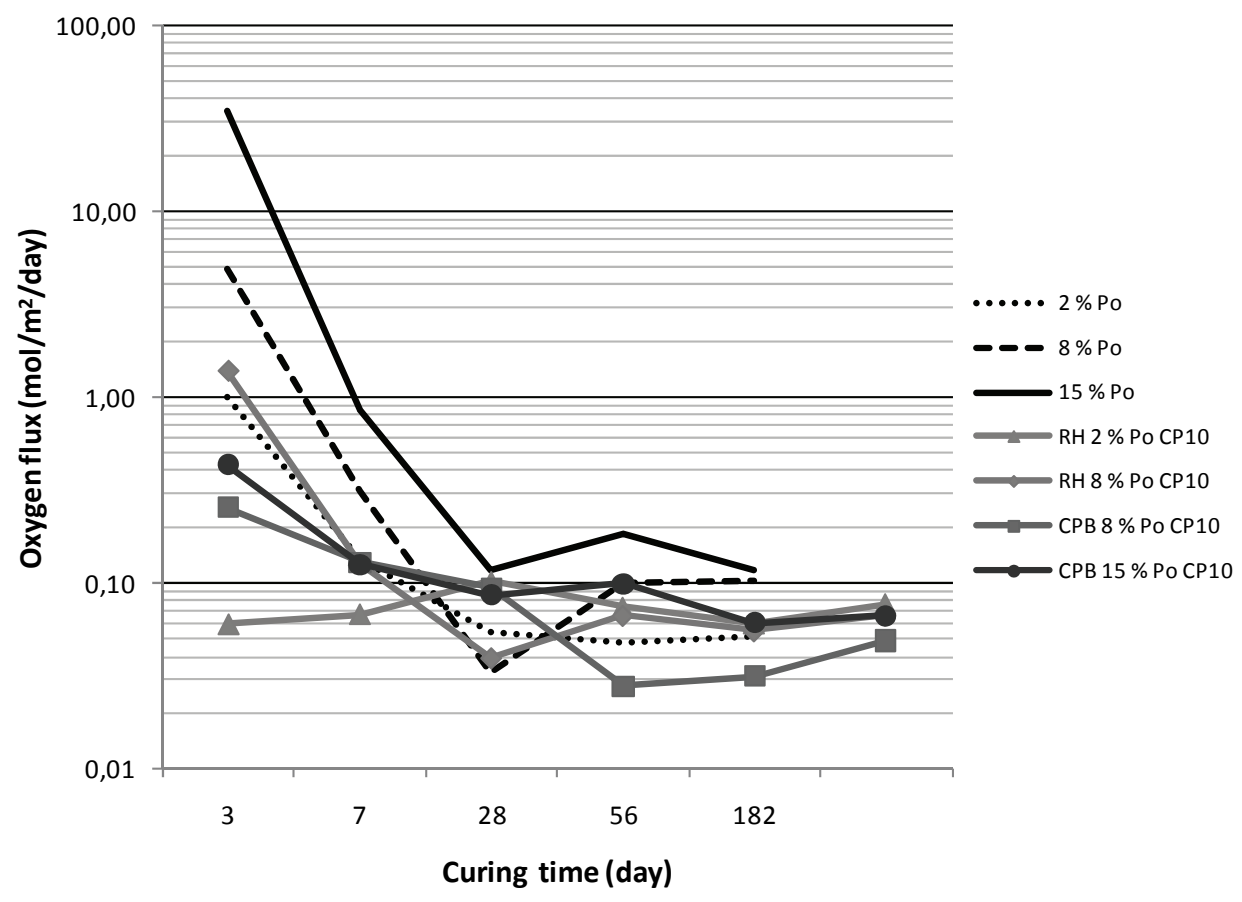

Figure 4 Oxygen flux evolution determined on the various tailings and cemented backfills

Figure 4 indicates that for all backfill mixtures, the difference between the consumed oxygen flux of the backfill and the control samples evolves with time. Initially, at short curing time $(<7$ days $)$ the tailings are significantly more reactive than the backfill mixture (a difference typically between 1 and 34 mol $\mathrm{O}_{2} / \mathrm{m}^{2} /$ day). This difference is reduced to values usually less than $0.1 \mathrm{~mol} \mathrm{O}_{2} / \mathrm{m}^{2} /$ day after 28 days of curing. Hence, with curing time greater than 28 days, oxygen fluxes consumed by the tailings with and without cement are relatively similar, for a given Po percentage. These results suggest that the addition of binder reduces the oxygen fluxes consumed by the tailings at short curing time. However, it appears that other factors, such as the degree of saturation of the material and possibly a pyrrhotite grains surface passivation, could influence the evolution of the pyrrhotite oxidation within backfill. Cruz et al. (2005) showed that the alteration (oxidation) of pyrrhotite involves the formation of layers that tend to coat and passivate the grains surface, reducing its reactivity. Benzaazoua (1996) also observed this passivation phenomenon induced by the presence of binders in paste backfilled containing pyrite and arsenopyrite.

Figure 4 also shows that the consumed oxygen fluxes of the paste backfill samples are usually lower (except at 28 days) than the corresponding hydraulic backfills samples (for a Po of $8 \%$ ). For example, the oxygen flux of the hydraulic backfill containing $8 \%$ pyrrhotite $\left(\mathrm{RH} 8 \%\right.$ Po $\left.\mathrm{CP}_{10}\right)$ at three days of hardening is approximately $1.4 \mathrm{~mol} / \mathrm{m}^{2} /$ day while the one of his vis-à-vis in paste (CPB $\left.8 \% \mathrm{Po} \mathrm{CP}_{10}\right)$ is approximately $0.3 \mathrm{~mol} \mathrm{O} / 2 / \mathrm{m}^{2} /$ day. For long curing time ( $>56$ days), the consumed oxygen flux of the hydraulic backfill is between 0.06 and $0.1 \mathrm{~mol} \mathrm{O}_{2} / \mathrm{m}^{2} /$ day compared to values between 0.02 and $0.05 \mathrm{~mol} \mathrm{O}_{2} / \mathrm{m}^{2} /$ day for the paste backfill sample.

\subsection{UCS test results}

Figure 5 shows the evolution of the UCS of hydraulic and paste backfills at different curing times. In this figure, each point represents the average of the three UCS tests results. 


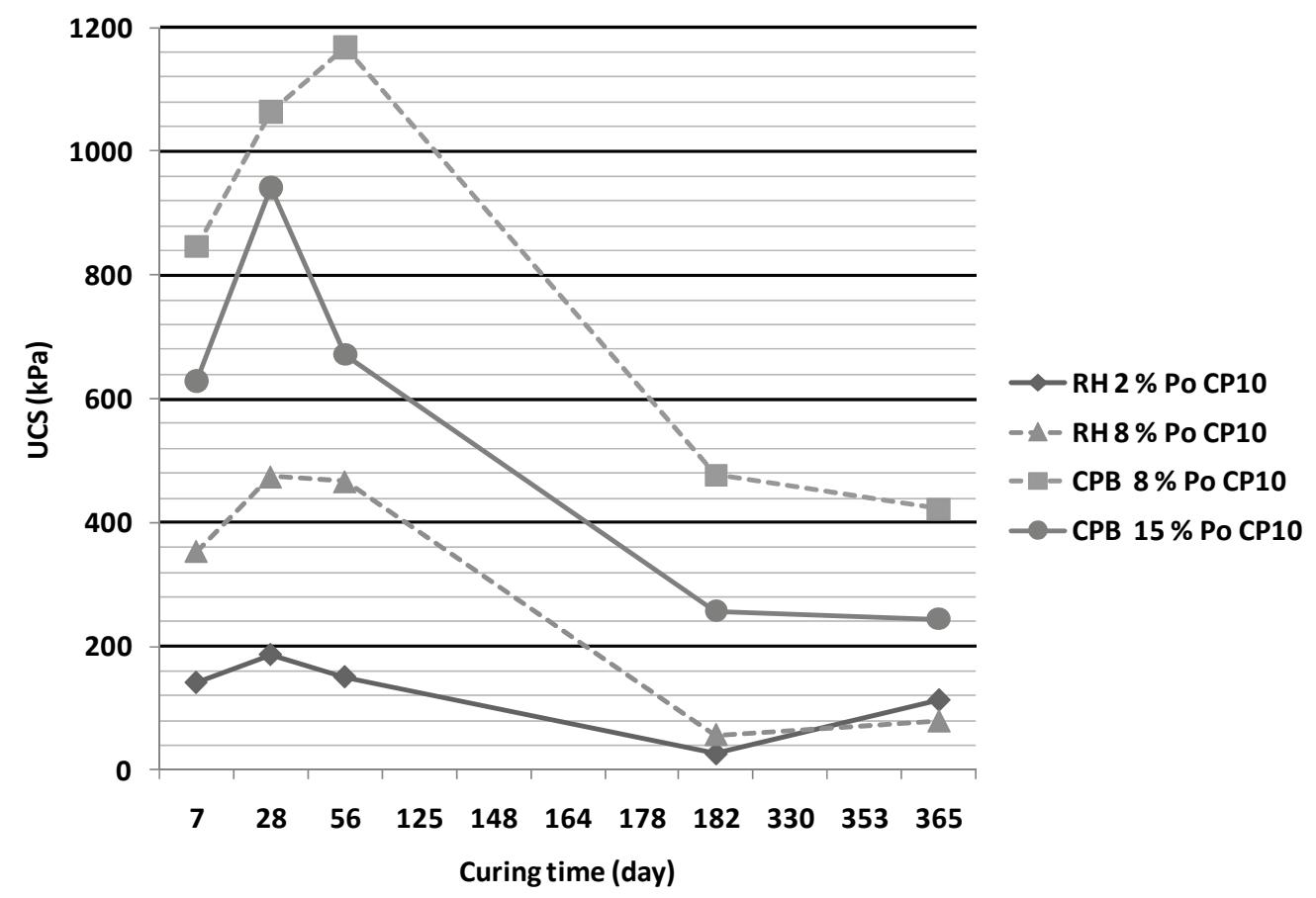

Figure 5 Evolution of the uniaxial compressive strength (UCS) of backfill mixtures

These results indicate that paste backfills reach and maintain higher UCS values compared to hydraulic corresponding backfills, for a similar Po content (at 8\% Po). The resistance of the hydraulic backfills does not exceed $500 \mathrm{kPa}$, whereas the UCS of the paste backfills mixture generally exceeds this value. Also, according to Figure 5, important losses of strength are observed. The UCS of the hydraulic backfill containing $8 \%$ Po $\left(\mathrm{RH} 8 \%\right.$ Po $\left.\mathrm{CP}_{10}\right)$ reached a value of approximately $475 \mathrm{kPa}$ at 56 days of hardening and dropped to approximately $80 \mathrm{kPa}$ after 365 days. The same phenomenon is observed for the paste backfill containing $8 \%$ Po (CPB 8\% Po $\mathrm{CP}_{10}$ ) which reached values higher than $1,000 \mathrm{kPa}$ after 56 days of curing but decreased to approximately $425 \mathrm{kPa}$ after 365 days. These losses of resistance could be attributed to sulphate attack. Previous investigations (Benzaazoua, 1996; Benzaazoua et al., 2004) indicate that sulphate precipitation can participate to the hardening processes early in the hydration process. However, precipitation of these hydrated sulphates (known for their important expansive effect) may produce sufficient intergranular pressures to affect negatively the hardened fill mass, causing a drop of its cohesion, and consequently of its strength.

To validate this hypothesis, post-testing samples were characterised for their mineralogy. The XRD mineralogical analysis of the backfill samples indicates the occurrence of sulphated cementing phases, represented by gypsum essentially, as well as a small amount of ettringite. Figures 6(a) and (b) present the results obtained for hydraulic backfill (in (a)) and paste backfill (in (b)) at 182 days of hardening. Globally, Figure 6 indicates that after 182 days of curing, the hydraulic backfills develop (as expected) more gypsum and ettringite than the paste backfills. These expansive minerals are known to be responsible for the loss of resistance in CPB (see Benzaazoua et al. 1999), which is in accordance with the UCS values observed (see Figure 5). 


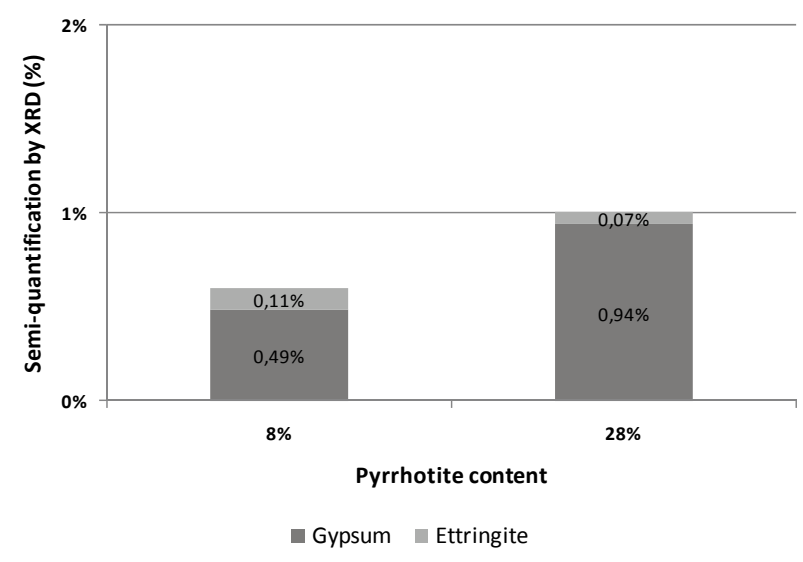

(a)

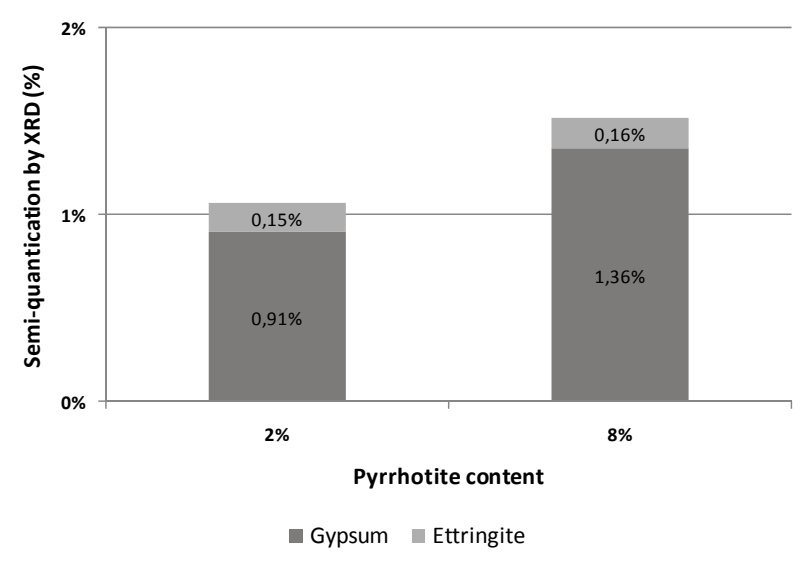

(b)

Figure 6 Proportions of sulphated phases developed in backfill mixtures at 182 days of curing: (a) Hydraulic backfills; (b) Paste backfills

However, it is worth mentioning that the quantification of the sulphated phases should be taken only as an indication, since the amount is small and the precision of the XRD is relatively low for this range of values (especially $<1 \%)$.

\subsection{Degree of saturation}

Figure 7 shows the evolution of the degree of saturation $\left(\mathrm{S}_{\mathrm{r}}\right)$ for the hydraulic and the paste backfills, during the tests (at a temperature of $30^{\circ} \mathrm{C}$ and a relative humidity of $100 \%$ ), between 7 and 365 days of curing.

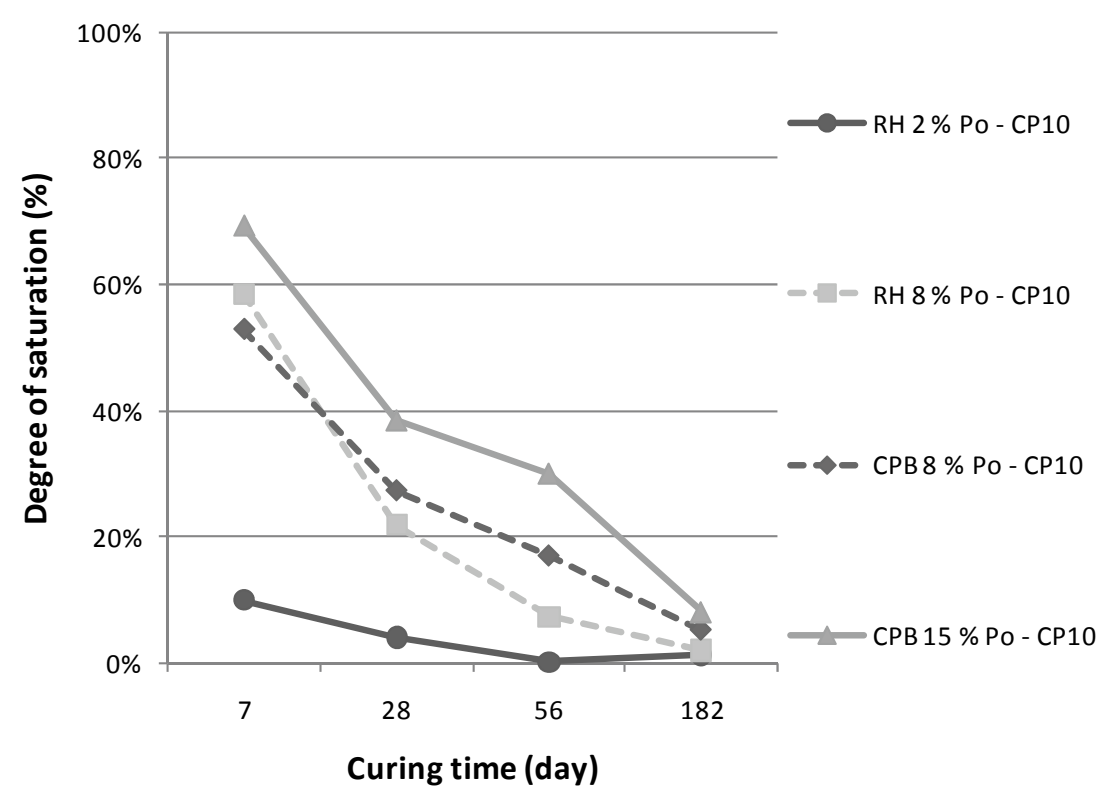

Figure 7 Evolution of the degree of saturation during curing of the backfills

These results show a decrease of $S_{\mathrm{r}}$ during curing for all backfill mixtures (hydraulic and paste). The comparison between these results and those presented in Figures 4 indicates that a higher reactivity is observed at short term curing time when the degree of saturation is between 45 and $75 \%$. Indeed, as observed in tailings by Gosselin (2007), at these degrees of saturation, the reactivity is optimal due to the presence of oxygen (the $D_{e}$ value is relatively high) and water simultaneously. At a very low degree of saturation, the lack of water to feed the oxidation reaction could also explain (at least in part) the low oxygen flux observed. These hypotheses are presently investigated further by the authors. 


\section{Conclusion}

The preliminary testing results presented here contribute to a better understanding of the mechanical and chemical behaviour of backfill containing pyrrhotite. OC tests results showed that tailings containing pyrrhotite (without binder) can be very reactive at $30^{\circ} \mathrm{C}$ when exposed to atmospheric oxygen concentration (with consumed oxygen fluxes greater than $35 \mathrm{~mol} / \mathrm{m}^{2} /$ day). The study also shows that the addition of a binding agent in the backfill mixtures reduces the tailings (or pyrrhotite) oxygen consumption in the short term; a more significant reduction was observed for paste backfill samples compared to hydraulic backfill specimens. UCS tests showed that paste backfill samples reached higher UCS values than hydraulic backfill for a given type and proportion of binder (at equal pyrrhotite content). However, loss of strength was observed for all backfill mixtures due to sulphate attack, as confirmed by the XRD mineralogical determination. The UCS reduction was more significant for the hydraulic backfill mixtures; the UCS values for the paste backfill samples with $8 \%$ Po remained higher than $500 \mathrm{kPa}$ after 365 days of hardening.

This study is providing additional information to identify the main influence factors on backfill reactivity. Besides the binder, this study suggests that other factors such as pyrrhotite grains coating (or passivation) and the degree of saturation may affect the evolution of the backfill reactivity.

\section{Acknowledgements}

This research was financed by the Institut de recherche Robert-Sauvé en santé et en sécurité du travail conjointly with an industrial partner. The industrial NSERC Polytechnique-UQAT Chair in Environment and Mine Wastes Management also contributed financially in the study. The authors would also like to thank the URSTM team for their technical support during the laboratory tests.

\section{References}

Aubertin, M., Bussière, B. and Bernier, L. (2002) Environnement et gestion des résidus miniers, Presses Internationales Polytechnique, Corporation de l'École Polytechnique de Montréal, Montréal, Manual on CD.

Bayah, J., Meech, J.A. and Stewart, G. (1984) Oxygen Depletion of Static Air by Backfill Material at the Thompson Mine; Mining Science and Technology, Vol. 1, pp. 93-106.

Benzaazoua, M., Marion, P., Picquet, I. and Bussière, B. (2004) The use of pastefill as a solidification and stabilization process for the control of acid mine drainage, Minerals Engineering, Vol. 17-2, pp. 233-243.

Benzaazoua, M., Belem, T. and Bussière, B. (2002) Chemical factors that influence on the performance of mine sulphidic paste backfill, Cement and Concrete Research, Vol. 32-7, pp. 1133-1144.

Benzaazoua, M., Belem, T. and Bussière, B. (2001) Mise en évidence du phénomène d'auto-ignition dans les remblais cimentés, Rapport FUQAT.

Benzaazoua, M. and Belem, T. (2000) Optimization of sulfide-rich paste backfill mixtures for increasing long-term strength and stability, in Proceedings 5th Conference on Clean Technology for Mining Industry, Santiago, Chile, M.A. Sánchez, F. Vergara and S.H. Castro (eds), University of Concepción, Vol. I, pp. 343-352.

Benzaazoua, M., Ouellet, J., Servant, S., Newman, P. and Verburg, R. (1999) Research, Cementatious Backfill with High Sulphur Content, Cement and Concrete, Vol. 29, No. 5, pp. 717-725.

Benzaazoua, M. (1996) Caractérisation physico-chimique et minéralogique de produits miniers sulfurés en vue de la réduction de leur toxicité et de leur valorisation, thèse de l'Institut National Polytechnique de Lorraine, Nancy, $267 \mathrm{p}$.

Bernier, L.R. and Li, M. (2003) High temperature oxydation (heating) of sulfidic paste backfill: A mineralogical and chemical perspective, Sudbury 2003, CD.

Bernier, L. and Li, M. (1998) Comparative analysis of oxidized and unaltered paste backfill specimens from Louvicourt mine, Internal Technical report prepared for Brunswick mining division, Noranda Inc. Bathurst, New Brunswick. $30 \mathrm{p}$.

Bertrand, V.J., Monroy, M.G. and Lawrence, R.W. (2000) Weathering characteristics of cemented paste backfill: mineralogy and solid phase chemistry, in Proceedings 5th International Conference on Acid Rock Drainage (ICARD), Denver, Colorado, Vol. II, pp. 863-876.

Cruz, R., González, I. and Monroy, M. (2005) Electrochemical characterization of pyrrhotite reactivity under simulated weathering conditions, Applied Geochemistry, Vol. 20, Issue 1, January 2005, pp. 109-121.

Elberling, B. and Damgaard, L.R. (2001) Microscale measurements of oxygen diffusion and consumption in subaqueous sulfide tailings, Geochimica and Cosmochimica Acta, Vol. 65, No. 12, pp. 1897-1905.

Elberling, B. and Nicholson, R.V. (1996) Field determination of sulfide oxidation rates in mine tailings, Water Resources Research, Vol. 32, pp. 1773-1784. 
Elberling, B., Nicholson, R.V., Reardon, E.J. and Tibble, P. (1994) Evaluation of sulphide oxidation rates: laboratory study comparing oxygen fluxes and rates of oxidation product release, Canadian Geotechnical Journal, Vol. 31, pp. 375-383.

Elberling, B., Nicholson, R.V. and David, D.J. (1993) Field evaluation of sulphide oxidation rates, Nordic Hydrology, Vol. 24, pp. 323-338.

Godbout, J. (2010) Influence of pyrrhotite content on the mechanical and chemical behaviour of cemented paste backfill, University of Quebec in Abitibi-Temiscamingue, Ph.D. Thesis (in preparation).

Gosselin, M. (2007) Étude de l'influence des caractéristiques hydrogéochimiques des résidus miniers réactifs sur la diffusion et la consommation de l'oxygène, Mémoire de maîtrise, École Polytechnique de Montréal, 246 p.

Liu, Q.K., Bernier, L. and Rosenblum, F. (1999) Preliminary investigation of the possible pastefill selfheating at Louvicourt Mine, Internal report, $91 \mathrm{p}$.

Mbonimpa, M., Aubertin, M., Aachib, M. and Bussière, B. (2003) Diffusion and consumption of oxygen in unsaturated cover materials, Canadian Geotechnical Journal, Vol. 40(5), pp. 916-932.

Mbonimpa, M., Aubertin, M., Dagenais, A-M., Bussière, B., Julien, M. and Kissiova, M. (2002) Interpretation of fields tests to determine the oxygen diffusion and reaction rate coefficients of tailings and soil covers, Ground and Water: Theory to Practice, in Proceedings 55th Canadian Geotechnical Conference, Niagara Falls, Ontario, Canada, October 20-23 2003, pp. 147-154.

Ouellet, S., Bussière, B., Mbonimpa, M., Benzaazoua, M. and Aubertin, M. (2006) Reactivity and mineralogical evolution of an underground mine sulphidic cemented paste backfill, Minerals Engineering, Vol. 19(5), pp. 407-419.

Ouellet, S., Bussière, B., Mbonimpa, M., Benzaazoua, M. and Aubertin, M. (2005) Reactivity and mineralogical evolution of an underground mine sulphidic cemented paste backfill, Minerals Engineering, Vol. 19, Issue 5, April 2006, pp. 407-419.

Ouellet, S., Bussière, B., Benzaazoua, M., Aubertin, M. and Belem, T. (2003) Sulphide reactivity within cemented paste backfill: oxygen consumption test results, 56th Annual Canadian Geotechnical Conference and 4th Joint IAHCNC and CGS Groundwater Specialty Conference, 29 September - 1 October 2003, Winnipeg, Manitoba, Comptes-Rendus sur CD.

Philips, M., Hockley, D. and Dawson, B. (2008) Sullivan mine fatalities incident: Initial technical investigation and findings, in Proceedings Hydrometallurgy 2008, 6th International symposium, Pheonix, August 17-20, 2008.

Rosenblum, F., Nesset, J. and Spira, P. (2001) Evaluation and control of self heating in sulphides concentrates, CIM Bulletin, Vol. 94, No. 1056, pp. 92-99.

Rosenblum, F. and Spira, P. (1995) Evaluation of hazard from self heating of sulphides rocks, CIM Bulletin, April, 1995, pp. 44-49.

Rosenblum, F., Spira, P. and Konigsmann, K.V. (1982) Evaluation of hazard from sulphide oxidation, In Proceedings 14th International Mineral Processing Congress, Paper IX-2.

Taylor, J.C. and Hinczak, I. (2001) Rietveld made easy: A Practical Guide to the Understanding of the Method and Successful Phase quantifications.

Tibble, P.A. and Nicholson, R.V. (1997) Oxygen consumption on sulphide tailings and covers: measured rates and applications, in Proceedings 4th International Conference on Acid Rock Drainage, Vancouver, Canada, Vol. 2, pp. 647-661. 
